\title{
Downregulation of microRNA-221 facilitates H1N1 influenza A virus replication through suppression of type-IFN response by targeting the SOCS1/NF-кB pathway
}

\author{
NALI ZHANG, YUAN MA, YUHENG TIAN, YAFEI ZHOU, YUHUA TANG and SHAOBO HU \\ Department of Respiratory Medicine and Intensive Care Unit, \\ Luoyang Central Hospital Affiliated to Zhengzhou University, Luoyang, Henan 471009, P.R. China
}

Received November 11, 2020; Accepted March 10, 2021

DOI: $10.3892 / \mathrm{mmr} .2021 .12136$

\begin{abstract}
Accumulating data has indicated that host microRNAs (miRNAs/miRs) play essential roles in innate immune responses to viral infection; however, the roles and the underlying mechanisms of miRNAs in influenza A virus (IAV) replication remain unclear. The present study examined on the effects of miRNAs on hemagglutinin $(\mathrm{H}) 1$ neuraminidase $(\mathrm{N}) 1$ replication and antiviral innate immunity. Using a microarray assay, the expression profiles of miRNA molecules in IAV-infected A549 cells were analyzed. The results indicated that miR-221 was significantly downregulated in IAV-infected A549 cells. It was also observed that IAV infection decreased the expression levels of miR-221 in A549 cells in a dose- and time-dependent manner. Functionally, upregulation of miR-221 repressed IAV replication, whereas knockdown of miR-221 had an opposite effect. Subsequently, it was demonstrated that miR-221 overexpression could enhance IAV-triggered IFN- $\alpha$ and IFN- $\beta$ production and IFN-stimulated gene expression levels, while miR-221-knockdown had the opposite effect. Target prediction and dual luciferase assays indicated that suppressor of cytokine signaling 1 (SOCS1) was a direct target of miR-221 in A549 cells. Furthermore, knockdown of SOCS1 efficiently abrogated the influences caused by miR-221 inhibition on IAV replication and the type-I IFN response. It was also found that the miR-221 positively regulated $\mathrm{NF}-\kappa \mathrm{B}$ activation in IAV-infected A549 cells. Taken together, these data suggested that miR-221-downregulation promotes IAV replication by suppressing type-I IFN response through targeting SOCS1/NF- $\kappa \mathrm{B}$ pathway. These findings suggest that miR-221 may serve as a novel potential therapeutic target for IAV treatment.
\end{abstract}

Correspondence to: Professor Nali Zhang, Department of Respiratory Medicine and Intensive Care Unit, Luoyang Central Hospital Affiliated to Zhengzhou University, 288 Middle Zhongzhou Road, Xigong, Luoyang, Henan 471009, P.R. China

E-mail: nalizhangnlz@sina.com

Key words: hemagglutinin 1 neuraminidase 1 influenza A virus, microRNA-221, type-I IFN response, SOCS1/NF-kB pathway

\section{Introduction}

Influenza A virus (IAV) is an enveloped negative-stranded RNA virus and its infection can result in both respiratory and constitutional effects, such as chills, headache, fever and general pain (1). In total, there are $>500,000$ IAV-associated human deaths worldwide each year, and several animal species with an elevated fatality rate from the virus have emerged (2). High levels of genetic diversity are the main cause of IAV pandemics, which represent a burden to human health $(3,4)$. Thus, it is important to explore new strategies against viral replication.

Innate immunity is the first barrier to the invasion of external pathogens. During viral infection, the innate immune system recognizes various pattern recognition receptors and then triggers downstream signal transduction, leading to the production of cytokines, especially type-I IFN $\alpha / \beta$ (5-7). Several studies have demonstrated that type-I IFNs effectively protect the host from IAV infection $(8,9)$. However, IAV can utilize a number of strategies to escape host innate immunity. For example, non-structural protein 1 (NS1) of IAV can inhibit the transcriptional activity of virus-induced interferon regulatory factor (IRF) 3, activator protein 1 and $N F-\kappa B$ signaling, disrupting the host antiviral immune response (10-12). In addition, Hayashi et al (13) demonstrated that a novel viral protein expressed by ribosomal frameshifting, PA-X, contributes to increased viral replication through the inhibition of host innate and acquired immune responses in mice. In addition to these proteins encoded by the virus itself, the virus uses host cell components to escape from the antiviral response, which restricts viral replication (13). However, how IAV counteracts the antiviral activity of type-I IFN remains poorly characterized.

MicroRNAs (miRNAs/miRs) are single-stranded non-coding RNA molecules that negatively regulate gene expression by binding to the 3'-untranslated region (UTR) of their target genes at the post-transcriptional level (14). Increasing evidence has demonstrated that miRNA suppresses type-I IFN production and inactivates the JAK-STAT pathway during infections with various types of virus (15-17). For example, infection with enterovirus can induce miR-146a expression, which suppresses the type-I IFN response of the 
host cell (18). Chen et al (19) reported that miR-21 was upregulated during hepatitis $\mathrm{C}$ virus ( $\mathrm{HCV}$ ) infection, which promoted viral replication by suppressing the type-I IFN-mediated antiviral response in hepatocytes. For IAV, Zhang et al (20) demonstrated that miR-132-3p suppressed the type-I IFN response by targeting IRF1 to facilitate hemagglutinin $(\mathrm{H}) 1$ neuraminidase (N)1 IAV infection. Zhu et al (21) demonstrated that miR-30e could inhibit dengue virus replication by upregulating IFN and IFN-stimulated gene (ISG) production. However, whether there are more miRNAs involved in regulating the innate immune response of host cells against IAV infection remains to be further explored.

It has previously been shown that miR-221 influences viral replication in several viruses, such as human cytomegalovirus (HCMV) and human papillomavirus 16 E1-E2, and that $\mathrm{miR}-221$ regulates innate antiviral immunity through IFN $\alpha / \beta$ (22,23). In addition, Du et al (24) also demonstrated that miR-221 negatively regulated the innate immune response and promoted vesicular stomatitis virus and herpes simplex virus type 1 replication. However, the role of miR-221 in IAV infection remains unclear. Therefore, miR-221 was investigated in the present study.

In the current study, the main research purpose was to elucidate the role and molecular mechanism of miR-221 in H1N1 IAV replication in the host cells. The miRNA expression profile of H1N1 IAV-infected A549 cells was investigated using a microarray assay. Subsequently, the role of miR-221 on H1N1 IAV replication was examined, and mechanisms underpinning the action of miR-221 in the immune response to IAV infection were investigated. The present findings may improve provide insight into the mechanism of IAV immune escape and highlight miR-221 as a potential novel target for the treatment of IAV infection.

\section{Materials and methods}

Cell culture. A549 cells were obtained from the American Type Culture Collection and cultured in minimum Eagle's medium (MEM; Gibco; Thermo Fisher Scientific, Inc.) supplemented with $10 \%$ fetal bovine serum, $100 \mathrm{U} / \mathrm{ml}$ penicillin and $100 \mu \mathrm{g} / \mathrm{ml}$ streptomycin at $37^{\circ} \mathrm{C}$ in a $5 \% \mathrm{CO}_{2}$ atmosphere.

Viral infection and plaque assay. The IAV/Jingfang/01/1986 (H1N1) strain was obtained from the Chinese Center for Disease Control and Prevention and was propagated in A549 cells. A549 cells were infected with H1N1 at a multiplicity of infection (MOI) of 0.1 . After $1 \mathrm{~h}$ of infection, the medium was discarded and the cells were washed with the free-serum medium, and then MEM with $1 \mu \mathrm{g} / \mathrm{ml}$ tosylsulfonyl phenylalanyl chloromethyl ketone (TPCK)-trypsin (Sigma-Aldrich; Merck KGaA) was added into duplicate wells. The cells uninfected with H1N1 were used as control (Mock) group. The copy number of virions were determined using qPCR detection of the matrix protein 2 (M2) gene, as later described. Viral titers in the supernatants were determined using a standard plaque assay. Briefly, A549 cells were seeded into 12 -well plates $\left(2 \times 10^{5}\right.$ cells/well $)$ and infected with $\mathrm{H} 1 \mathrm{~N} 1$ in $1: 10$ dilutions for $60 \mathrm{~min}$ at $37^{\circ} \mathrm{C}$. Then, $1 \%$ low-melting-point agarose (Sigma-Aldrich; Merck KGaA) in $500 \mu 1$ MEM (Gibco; Thermo Fisher Scientific, Inc.) containing $1 \mu \mathrm{g} / \mathrm{ml}$ TPCK trypsin were added to the wells. Plates were incubated at $37^{\circ} \mathrm{C}$ with $5 \% \mathrm{CO}_{2}$ for $72 \mathrm{~h}$ and then were fixed for $2 \mathrm{~h}$ at room temperature with $4 \%$ paraformaldehyde. Fixed cells were washed extensively with PBS before staining with crystal violet $(0.1 \%$ in $10 \%$ ethanol) for $30 \mathrm{~min}$ at room temperature.

Microarray analysis. RNA was extracted from A549 cells infected and uninfected with $\mathrm{H} 1 \mathrm{~N} 1$ influenza virus using a mirVana ${ }^{\mathrm{TM}}$ miRNA Isolation kit (Thermo Fisher Scientific, Inc.), then the RNA concentration was analyzed using a NanoDrop ${ }^{\mathrm{TM}} 2000$ spectrophotometer (NanoDrop Technologies; Thermo Fisher Scientific, Inc.). Total RNA (1 $\mu \mathrm{g})$ was labeled using the miRCURY LNA ${ }^{\mathrm{TM}} \mathrm{Hy}^{\mathrm{TM}} / \mathrm{Hy} 5^{\mathrm{TM}}$ Power labeling kit (cat no. 208032-A; Exiqon A/S). Subsequently the samples were hybridized on the miRCURY ${ }^{\mathrm{TM}}$ LNA Array (version 16.0; cat. no. 208040; Exiqon A/S) according to the manufacturer's protocol. The procedure and imaging processes were performed as described previously (20).

Reverse transcription-qPCR (RT-qPCR). Total RNA was extracted from cells using TRIzol ${ }^{\circledR}$ (Invitrogen; Thermo Fisher Scientific, Inc.). RNA was then reverse transcribed into cDNA using the PrimeScript ${ }^{\mathrm{TM}}$ RT reagent kit (cat no. RR047A; Takara Bio, Inc.) or the TaqMan ${ }^{\mathrm{TM}}$ MicroRNA Reverse Transcription kit (cat no. 4366596; Thermo Fisher Scientific, Inc.) according to the manufacturer's protocol, respectively. For detection of miR-221 and mRNAs, qPCR was conducted using SYBR $^{\circledR}$ PrimeScript ${ }^{\mathrm{TM}}$ RT-PCR kit (Takara Bio, Inc.) on ABI 7900HT Fast Real-Time PCR system (Applied Biosystems; Thermo Fisher Scientific, Inc.). U6 and GAPDH were used as internal controls for detecting miR-221 and mRNA targets, respectively. The thermocycling conditions were as follows: Initial denaturation at $95^{\circ} \mathrm{C}$ for $1 \mathrm{~min}$, followed by 40 cycles of $95^{\circ} \mathrm{C}$ for $30 \mathrm{sec}, 58^{\circ} \mathrm{C}$ for $30 \mathrm{sec}$ and $68^{\circ} \mathrm{C}$ for $2 \mathrm{~min} / \mathrm{kb}$, followed by $68^{\circ} \mathrm{C}$ for $10 \mathrm{~min}$. The primer sequences were listed as follows: i) miR-221 forward (F), 5'-GGGAAGCTACATTGT CTGC-3' and reverse (R), 5'-CAGTGCGTGTCGTGGAGT-3'; ii) U6 F, 5'-GCTTCGGCAGCACATATACTAAAAT-3' and R, 5'-CGCTTCAGAATTTGCGTGTCAT-3'; iii) suppressor of cytokine signaling 1 (SOCS1) F, 5'-CTGCGGCTTCTATTG GGGAC-3' and R, 5'-AAAAGGCAGTCGAAGGTCTCG-3'; iv) 2'-5'-oligoadenylate synthase 2 (OAS) F, 5'-AGGTGGTAA AGGGTGGCT-3' and R, 5'-TGCTTGACTAGGCGGATG-3'; v) interferon-inducible double-stranded RNA-dependent protein kinase activator A (PKR) F, 5'-AGAGTAACCGTTGGTGAC ATAACCT-3' and R, 5'-GCAGCCTCTGCAGCTCTATGTT-3'; vi) viperin, F, 5'-CAAGACCGGGGAGAATACCTG-3' and R, 5'-GCGAGAATGTCCAAATACTCACC-3'; vii) myxovirus resistance protein 1 (MxA) F, 5'-GGGAAGGTGAAGGTC GGAGT-3' and R, 5'-TTGAGGTCAATGAAGGGGTCA-3'; viii) M2 F, 5'-GACCGATCCTGTCACCTCTGAC-3' and R, 5'-AGGGCATTCTGGACAAAGCGTCTA-3'; and ix) GAPDH F, 5'-AGCTTGTCATCAACGGGAAG-3' and R, 5'-TTTGAT GTTAGTGGGGTCTCG-3'. Changes in the expression of each gene were calculated using the $2^{-\Delta \Delta \mathrm{Cq}}$ method (25).

Transfection. A549 cells were cultured to $70 \%$ confluence, then transfection of miR-221 mimics (100 nM), miR-221 inhibitor (100 nM), mimics negative control (NC; $100 \mathrm{nM})$, inhibitor 
NC (100 nM), and small interfering RNA SOCS (si-SOCS1) (20 nM) or si-scramble (20 nM) (Shanghai GenePharma Co., Ltd.) were performed at $37^{\circ} \mathrm{C}$ for $24 \mathrm{~h}$ using Lipofectamine ${ }^{\circledR}$ 2000 (Invitrogen; Thermo Fisher Scientific, Inc.) according to the manufacturer's instructions. The mimics NC, inhibitor NC and si-Scramble were non-targeting. Non-transfected cells are used as the Blank group. After $24 \mathrm{~h}$ the transfection, H1N1 virus were added in the cells at an MOI of 0.1. The cells were harvested at 12 or $24 \mathrm{~h}$ post-infection for testing.

ELISA. After $12 \mathrm{~h}$ or $24 \mathrm{~h} \mathrm{H1N1}$ virus infection, cell culture supernatants were collected and the levels of IFN- $\alpha$ and IFN- $\beta$ were measured with human IFN- $\alpha$ kit (cat. no. 32400-1) kit and a human IFN- $\beta$ ELISA kit (cat. no. 32100-1) (both Pestka Biomedical Laboratories, Inc.).

Luciferase reporter $N F-\kappa B$ activity assays. PicTar (March 2007 release; http://pictar.mdc-berlin.de/) and TargetScan (version 7.2; http://www.targetscan.org) were used to search for the putative targets of miR-221.The wild-type (wt) 3'-UTR of SOCS1 and the mutated (mut) sequence were inserted into the pGL3 control vector (Promega Corporation) to construct the wt and mut SOCS1-3'-UTR vectors, respectively. A549 cells were transfected with miR-221 mimics/inhibitor, respective NCs and these luciferase reporter plasmids using Lipofectamine. After 48 h, luciferase activity was assessed using the Dual-luciferase ${ }^{\circledR}$ Reporter Assay system (cat. no. E1910; Promega Corporation). Renilla luciferase activity was used to normalize firefly luciferase activity. The NF- $\kappa \mathrm{B}$ activity was assessed as previously described (26). Luciferase activity was quantified using the aforementioned kit on a luminometer.

Western blotting. Total protein was obtained from A549 cells transfected as aforementioned using RIPA lysis buffer (Beyotime Institute of Biotechnology) and quantified using a BCA protein assay kit (Pierce ${ }^{\mathrm{TM}}$; Thermo Fisher Scientific, Inc.). Next, protein samples (40 $\mu \mathrm{g} /$ lane) in the lysates were separated by $12 \%$ SDS-PAGE gels and transferred to PVDF membranes (GE Healthcare) followed by incubation in a $5 \%$ skimmed milk solution for $1 \mathrm{~h}$ at room temperature. Subsequently, the specific primary antibodies were incubated in the membranes at $4^{\circ} \mathrm{C}$ overnight, including mouse anti-M1 monoclonal antibody and rabbit anti-nucleoprotein (NP) polyclonal antibody that were kindly provided by Dr Wenjun Liu (Institute of Microbiology; Chinese Academy of Sciences), SOCS1 (cat. no. 68631; 1:1,000 dilution), NF- $\kappa \mathrm{B}$ inhibitor $\alpha$ (IкB- $\alpha$; cat. no. 4814; 1:1,000 dilution), phosphorylated

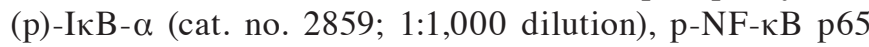
(cat. no. 3033; 1:1,000 dilution), NF- $\mathrm{B}$ p65 (cat. no. 8242; $1: 1,000$ dilution) and $\beta$-actin (cat. no. 3700; 1:1,000 dilution) (all Cell Signaling Technology, Inc.). Subsequently, the corresponding anti-mouse or anti-rabbit IgG HRP-conjugated secondary antibodies (cat no. 4409 and 3678, respectively; both 1:2,000; Cell Signaling Technology, Inc.) were added into the membranes for $2 \mathrm{~h}$ at room temperature. The protein bands were detected using chemiluminescence with Pierce ECL kits (Thermo Fisher Scientific, Inc.). Semi-quantification was performed using ImageJ version 1.46 (National Institutes of Health).
Statistical analysis. Statistical analysis was performed using the SPSS 13.0 software package (SPSS Inc.). All data are presented as the mean $\pm \mathrm{SD}$, and each experiment was repeated at least three times. The two-group comparisons were conducted using unpaired Student's t-test. Comparisons among multiple groups were performed using one-way ANOVA followed by Tukey's post hoc test. $\mathrm{P}<0.05$ was considered to indicate a statistically significant difference.

\section{Results}

miR-221 is downregulated in H1N1 IAV-infected cells. To investigate the potential roles of miRNAs in antiviral responses to IAV, a microarray assay was performed using extracted RNA from H1N1-infected A549 cells or uninfected cells. The results showed that 46 miRNAs had significantly altered expression levels in H1N1 IAV-infected A549 cells compared with the control cells. These miRNAs included 26 downregulated and 20 upregulated miRNAs (Fig. 1A). Among the downregulated miRNAs, miR-221 was one of the most notably downregulated miRNAs, which is consistent with a previous study (27). However, the role of miR-221 in IAV infection remains unclear. Therefore, miR-221 was chosen for subsequent experiments.

To validate the expression of miR-221 obtained from the microarray assay, miR-221 expression in A549 cells was examined at different time points of IAV infection. It was observed that miR-221 expression was significantly downregulated in H1N1 IAV-infected A549 cells during the virus infection, especially in the early stages of infection (Fig. 1B). Since the innate antiviral immune response occurs at early stage of IAV infection (28), it was hypothesized that miR-221 may affect IAV infection by regulating the innate antiviral immune response. The miR-221 levels in A549 cells infected with different MOIs of IAV were also measured. miR-221 expression was downregulated in IAV-infected A549 cells in a dose-dependent manner (Fig. 1C). Collectively, these results suggested that miR-221 may be involved in IAV infection.

miR-221 regulates IAV replication in A549 cells. To investigate the biological function of miR-221 in IAV infection, A549 cells were transfected with miR-221 mimics or miR-221 inhibitor. As shown in Fig. 2A and D, miR-221 expression significantly increased in A549 cells after miR-221 mimics transfection, and significantly decreased after miR-221 inhibitor transfection. Following by H1N1 infection, plaque assay results showed that the viral titers and the viral copy numbers of IAV were significantly decreased by miR-221 mimics transfection, and increased by the miR-221 inhibitor (Fig. 2B, C, E and F). NP and M1 are two of the most abundant proteins in the virion, which are relatively well-conserved and display limited antigenic change $(29,30)$. Thus, it was investigated whether miR-221 affects the protein levels of NP and M1 in IAV-infected A549 cells. The results showed that the protein levels of NP and M1 were significantly reduced by miR-221 upregulation, but increased by miR-221-knockdown (Fig. 2G and H). These results suggested that miR-221 negatively regulated IAV replication.

Overexpression of miR-221 increases IAV-triggered type-I IFN production in A549 cells. It is recognized that the type-I 
A

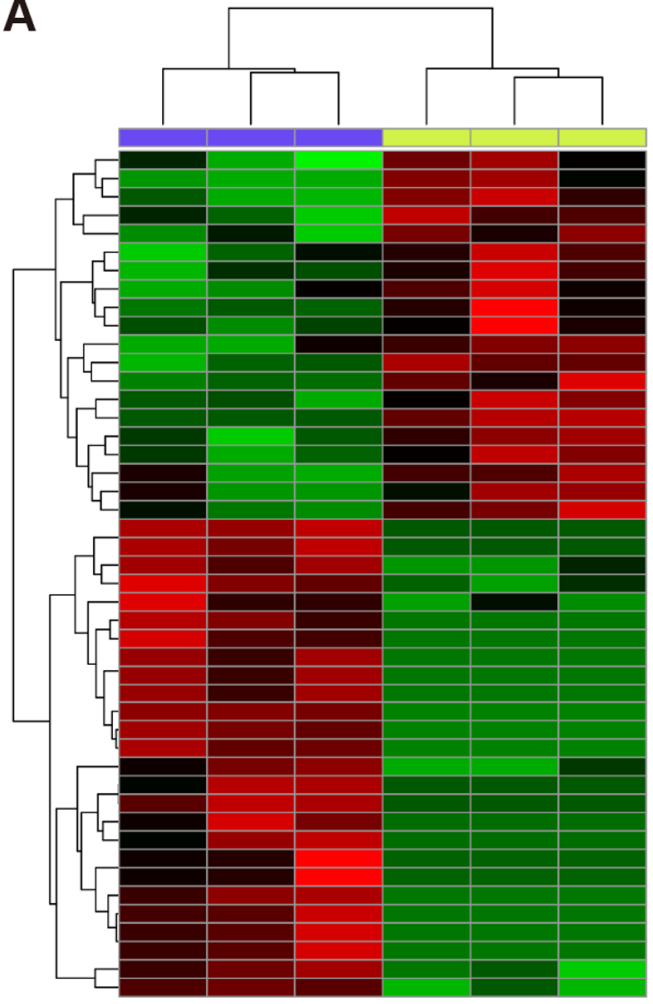

B

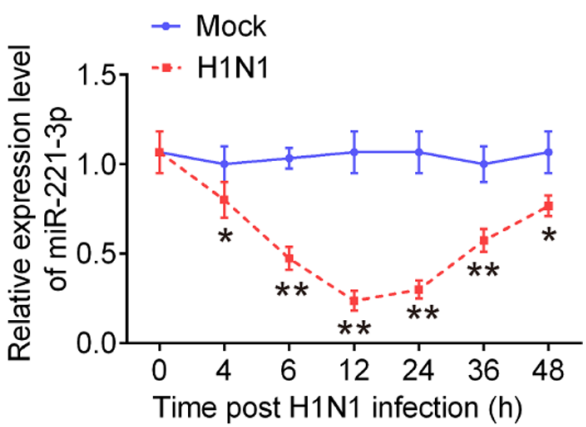

C

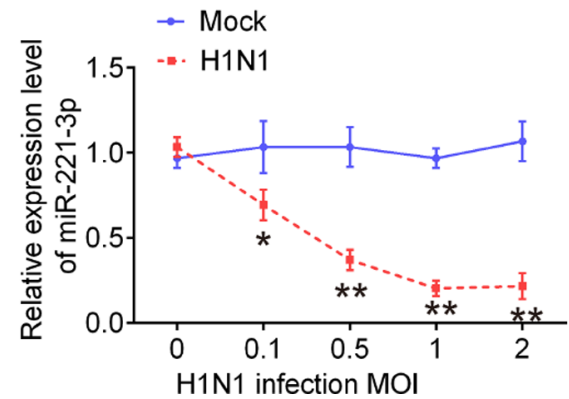

Figure 1. miR-221 expression is downregulated during IAV infection. (A) Heatmap of normalized expression levels of miRNAs in IAV-infected A549 cells and control cells $(n=3)$. Green indicates low expression levels; red indicates high expression levels. A549 cells were infected with IAV either at indicated time at (B) a MOI of 1 or at (C) indicated MOIs for $24 \mathrm{~h}$, then the cells were harvested for further reverse transcription-quantitative PCR analysis of miR-221 expression. Data are presented as the mean $\pm \mathrm{SD}$ of three individual experiments. ${ }^{*} \mathrm{P}<0.05$ and ${ }^{* * *} \mathrm{P}<0.01$ vs. mock group. IAV, influenza A virus; MOI, multiplicity of infection; miR, microRNA; hsa, Homo sapiens; H1N1, hemagglutinin 1 neuraminidase 1.

IFN immune response plays critical roles in the initial antiviral response (31). To test whether miR-221 regulates the type-I IFN immune response, the expression of cytokines (IFN- $\alpha$ and IFN- $\beta$ ) and ISGs (MxA, OAS, viperin and PKR) was measured. As shown in Fig. 3A and B, miR-221-overexpression enhanced the expression of IFN- $\alpha$ and IFN- $\beta$ at protein levels in A549 cells in response to IAV infection. Moreover, similar results were observed for ISG mRNA expression during IAV infection, as determined by RT-qPCR analysis (Fig. 3C-F). These data indicated that overexpression of miR-221 facilitated the innate immune response and subsequently inhibited IAV replication in A549 cells.

Knockdown of miR-221 decreases IAV-triggered type-I IFN production in A549 cells. To confirm whether miR-221 inhibition affects the type-I IFN immune response during IAV infection, A549 cells were transfected with miR-221 inhibitor, followed by IAV infection. As shown in Fig. 4A and B, inhibition of miR-221 significantly reduced IFN- $\alpha$ and IFN- $\beta$ protein expression levels in IAV-infected A549 cells. RT-qPCR analysis demonstrated that transfection with the miR-221 inhibitor reduced the expression levels of these ISGs in IAV-infected A549 cells (Fig. 4C-F). These data indicated that miR-221 downregulation may promote IAV replication by inhibiting the innate immune response in A549 cells.

SOCS1 is a direct target of miR-221 in IAV-infected A549 cells. To determine the possible mechanism of miR-221 in the regulation of IAV replication, the target genes of miR-221 were identified. Using the TargetScan and PicTar algorithms, the complementary sequence of miR-221 was identified in the 3'-UTR of SOCS1 mRNA (Fig. 5A). To verify whether SOCS1 was directly regulated by miR-221, a dual-luciferase reporter assay was performed. The results showed that miR-221 mimics significantly decreased the luciferase activity of wt-SOCS1 3'UTR compared with the mimics $\mathrm{NC}$, while miR-221 inhibitor increased the luciferase activity compared with inhibitor NC treatment (Fig. 5B). However, the effects produced by miR-221 were abrogated in the cells transfected with the vector bearing the mut SOCS1 3'-UTR (Fig. 5B). To further validate this conclusion, the mRNA and protein expression level of SOCS1 was examined in A549 cells transfected with the miR-221 mimic or inhibitor. SOCS1 expression was significantly decreased when miR-221 was overexpressed, but increased at the mRNA and protein expression levels when the miR-221 inhibitor was transfected (Fig. 5C and D). Additionally, the mRNA levels of SOCS1 in A549 cells during H1N1 infection was verified. As shown in Fig. 5E, SOCS1 mRNA expression levels were time-dependently increased and reached the peak at $24 \mathrm{~h}$ after IAV infection. Subsequently, the mRNA expression level of SOCS1 decreased slightly at $48 \mathrm{~h}$. In addition, its mRNA expression levels were also upregulated in a dose-dependent manner (Fig. 5F). Taken together, these data suggested that SOCS1 was a direct target of miR-221 in A549 cells during infection of H1N1.

Knockdown of SOCS1 reverses the promoting effects of miR-22-downregulation on IAV replication. Since SOCS1 
A

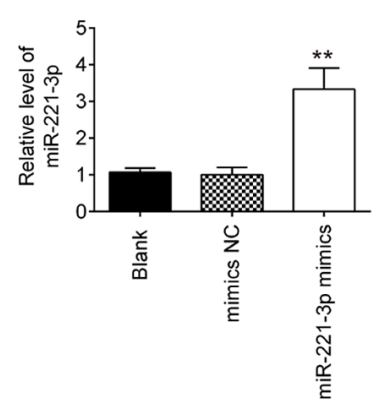

D

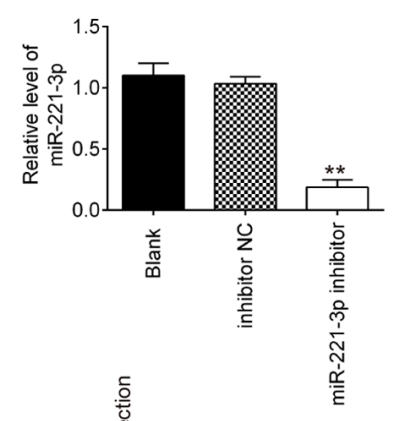

B

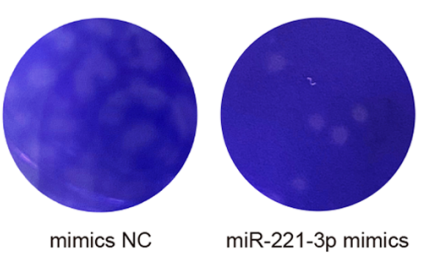

E
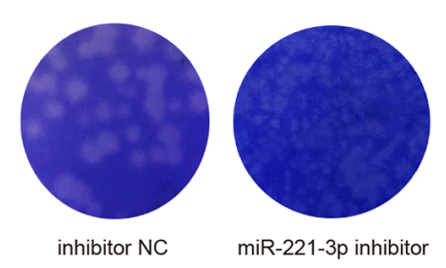

miR-221-3p inhibitor

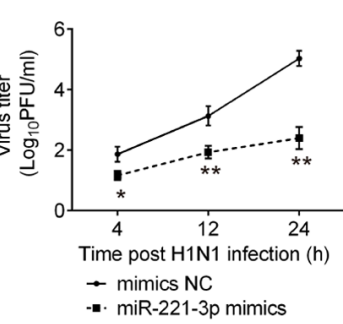

- miR-221-3p mimics

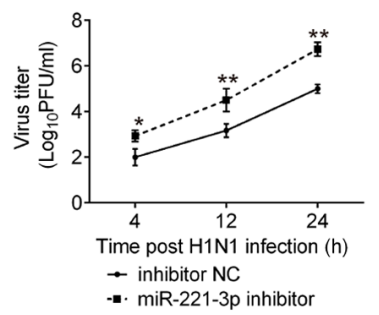

C

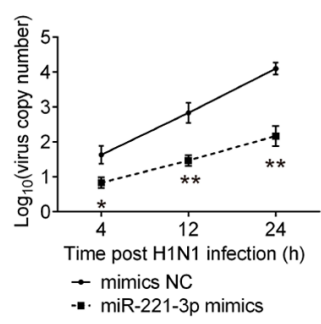

F

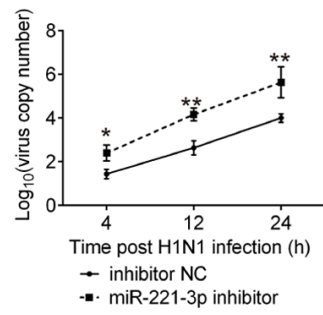

G

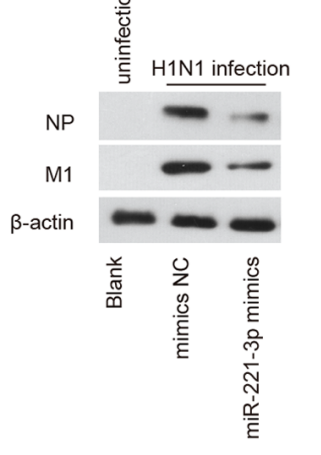

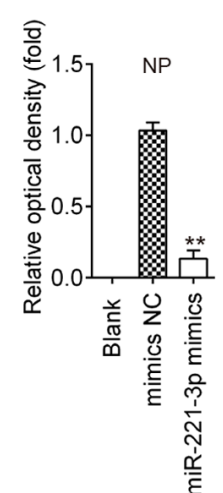

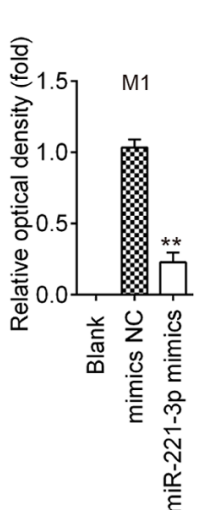

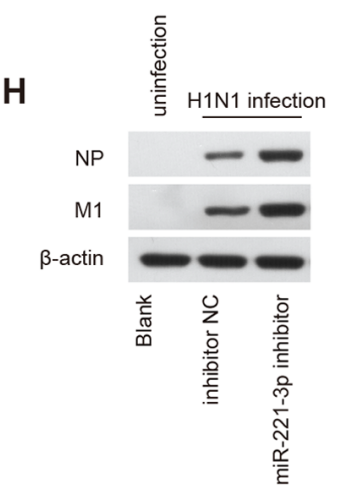

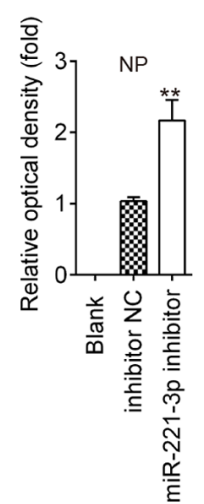

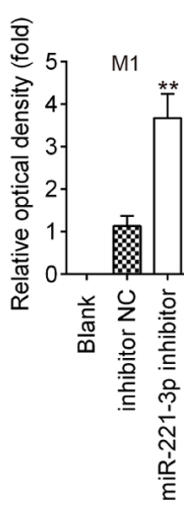

Figure 2. miR-221 negatively regulates IAV replication. (A) Transfection efficiency of miR-221 mimics was determined using RT-qPCR. (B) After miR-221 mimics transfection, viral titers in the cell cultures were determined by plaque assay using 12-well plates. (C) After miR-221 mimics transfection, copy number of virions of H1N1 was measured using qPCR. (D) Transfection efficiency of miR-221 inhibitor was determined using RT-qPCR. (E) After miR-221 inhibitor transfection, viral titers in the cell cultures were determined via a plaque assay using 12-well plates. (F) After miR-221 inhibitor transfection, copy number of virions of H1N1 was measured using qPCR. (G and H) Levels of M1 and NP protein expression levels were determined using western blotting. ${ }^{*} \mathrm{P}<0.05$ and ${ }^{* *} \mathrm{P}<0.01$ vs. mimics NC or inhibitor NC. NC, negative control; IAV, influenza A virus; miR, microRNA; M1, matrix protein 1; NP, nucleoprotein; H1N1, hemagglutinin 1 neuraminidase 1; RT-qPCR, reverse transcription-quantitative PCR; PFU, plaque-forming unit.

is essential for the induction of type-I IFNs during host defense $(22,32)$, it was hypothesized that miR-221 facilitates IAV replication by regulating type-I IFN production by targeting SOCS1. Therefore, miR-221 inhibitor and si-SOCS1 were co-transfected into A549 cells, then infected with IAV. In A549 cells transfected with si-SOCS1, SOCS1 protein expression levels were significantly reduced compared with that in the si-Scramble-transfected cells (Fig. 6A). As shown in Fig. 6B, the viral titers of IAV were significantly increased when miR-221 inhibitor was transfected, compared with the inhibitor NC group. However, after co-transfection of si-SOCS1, the viral titers were significantly reduced compared with miR-221 inhibitor group. Subsequently, the effects of si-SOCS1 on the expressions of IFNs and ISGs were examined in IAV-infected A549 cells. The miR-221 inhibitor significantly suppressed the expression levels of IFNs and ISGs, while the inhibitory effects of miR-221 inhibitor against the type-I IFN response were reversed by SOCS1-knockdown (Fig. 6C-H). All these data suggested that miR-221 inhibition facilitated H1N1 IAV replication by targeting SOCS1.

miR-221 positively regulates the SOCS1-mediated activation of the $N F-\kappa B$ pathway. SOCS1 has been previously implicated in the regulation of NF- $\mathrm{NB}$ pathway, which can induce the expression of antiviral genes such as type I in IFNs and ISGs (33). To investigate the effect of miR-221 on the activity of the NF- $\kappa \mathrm{B}$ signaling pathway, the expression levels of downstream proteins in the NF- $\mathrm{B}$ signaling pathway, namely nuclear p-p65, p-IкB- $\alpha$ and I $\kappa$ B- $\alpha$ were evaluated. As shown in Fig. 7A and B, miR-221-overexpression significantly reduced the expression levels of SOCS1, and increased the expression levels of nuclear p-p65 and p-IкB- $\alpha$, while miR-221 inhibition had opposite effects in IAV-infected A549 cells. In addition, the NF- $\kappa \mathrm{B}$ reporter luciferase activity was significantly increased by miR-221-overexpression, whereas decreased by miR-221 inhibition (Fig. 7C). Overall, these results demonstrated that miR-221 positively regulated the SOCS1-mediated activation of the NF- $\mathrm{NB}$ pathway in IAV-infected cells. 
A

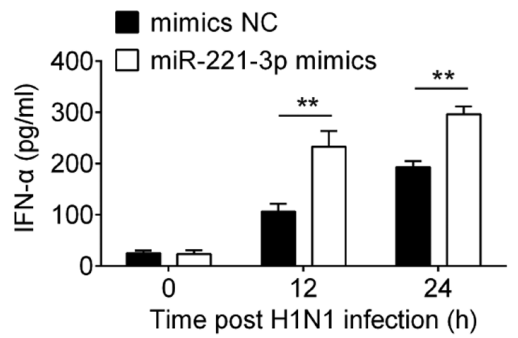

C

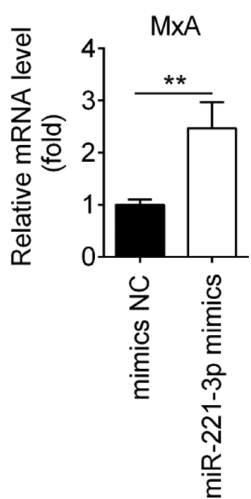

D

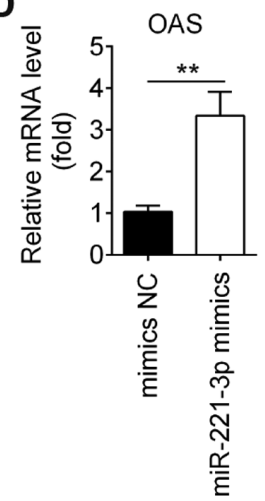

B

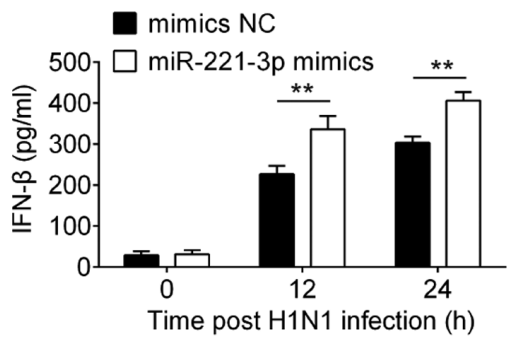

E

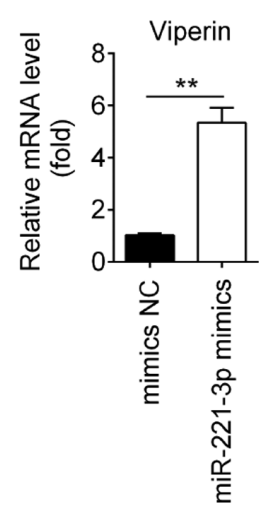

$\mathbf{F}$

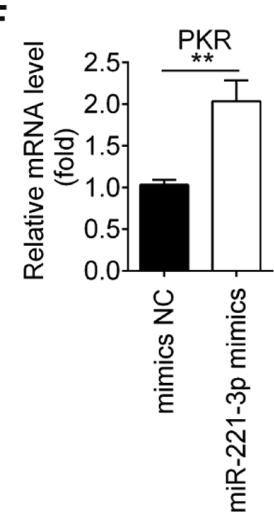

Figure 3. miR-221 overexpression enhances IAV-triggered type-I IFN production in A549 cells. (A and B) Cell and supernatants were harvested at 0,12 and $24 \mathrm{~h}$ post-infection, and then ELISA assay was performed to measure IFN- $\alpha$ and IFN- $\beta$ expression. (C-F) Reverse transcription quantitative-PCR assay was performed to measure the expression of IFN-stimulated genes (MxA, OAS, viperin and PKR). Data are presented as the mean \pm SD of three individual experiments. ${ }^{* *} \mathrm{P}<0.01$ vs. mimics NC group. NC, negative control; IAV, influenza A virus; miR, microRNA; OAS, 2'-5'-oligoadenylate synthase 2; MxA, myxovirus resistance protein 1; PKR, interferon-inducible double-stranded RNA-dependent protein kinase activator A.

A

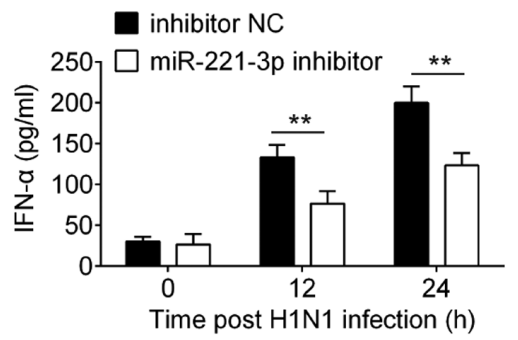

C

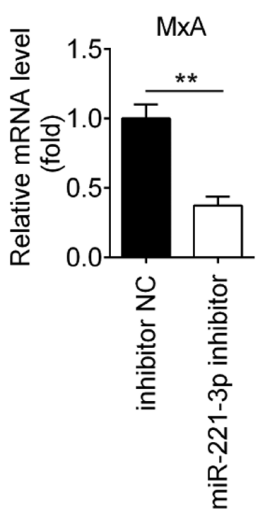

B
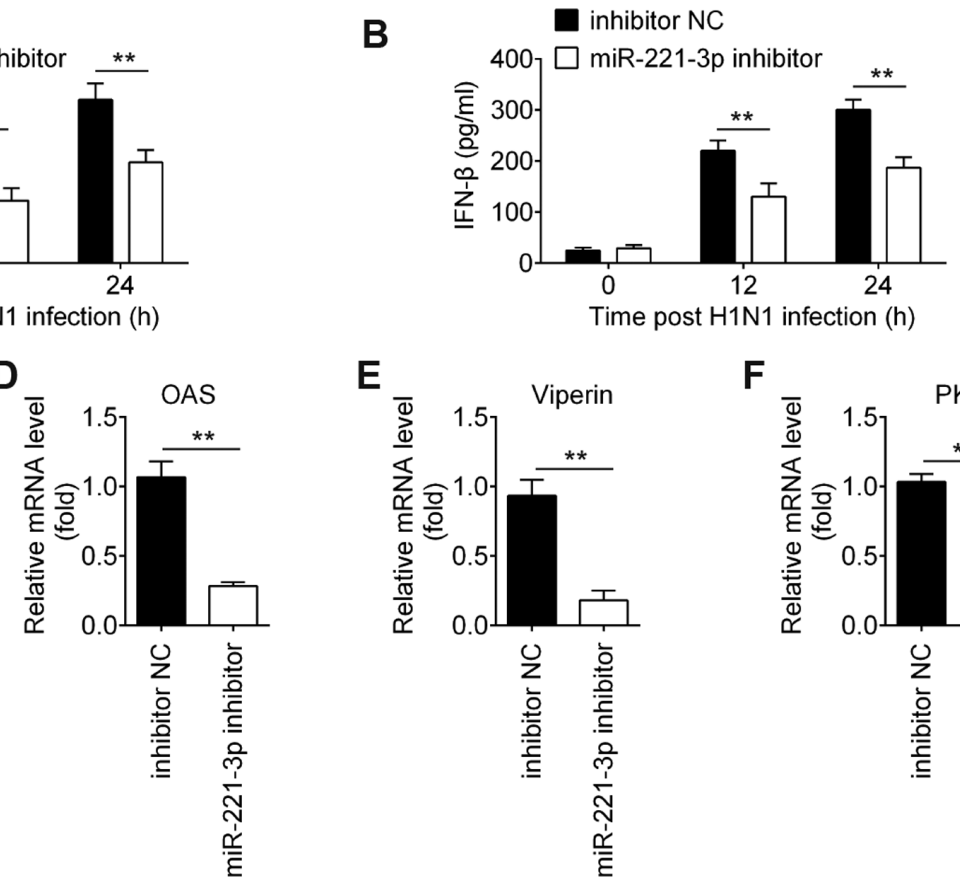

E

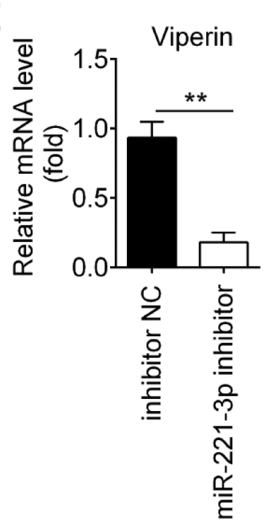

$F$

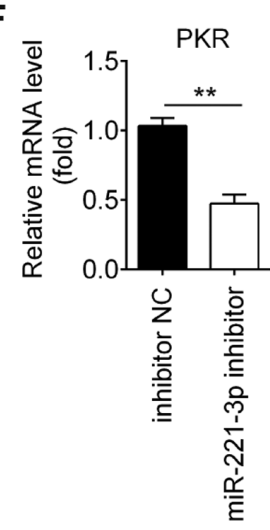

Figure 4. miR-221-knockdown suppresses IAV-triggered type-I IFN production in A549 cells. (A and B) Cell and supernatant were harvested at 0, 12 and $24 \mathrm{~h}$ post-infection, and then ELISA assay was performed to measure IFN- $\alpha$ and IFN- $\beta$ expression. (C-F) Reverse transcription quantitative-PCR was performed to measure the expression of IFN-stimulated genes (MxA, OAS, viperin and PKR). Data are presented as the mean \pm SD of three individual experiments. ${ }^{* *} \mathrm{P}<0.01$ vs. inhibitor NC group. NC, negative control; IAV, influenza A virus; miR, microRNA; OAS, 2'-5'-oligoadenylate synthase 2; MxA, myxovirus influenza resistance 1; PKR, interferon-inducible double-stranded RNA-dependent protein kinase activator A.

\section{Discussion}

In the present study, the expression of miR-221 was significantly downregulated in A549 cells infected with H1N1.
Notably, miR-221 inhibition facilitated H1N1 replication by alleviating the antiviral defense of host cells by targeting the SOCS1/NF- $\kappa$ B pathway. The current findings identified a novel strategy used by IAV to escape IFN-I-mediated antiviral 
A

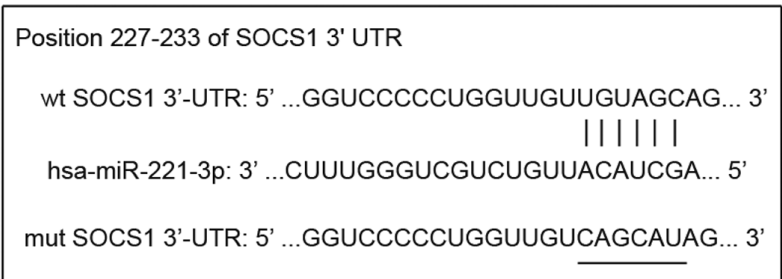

C

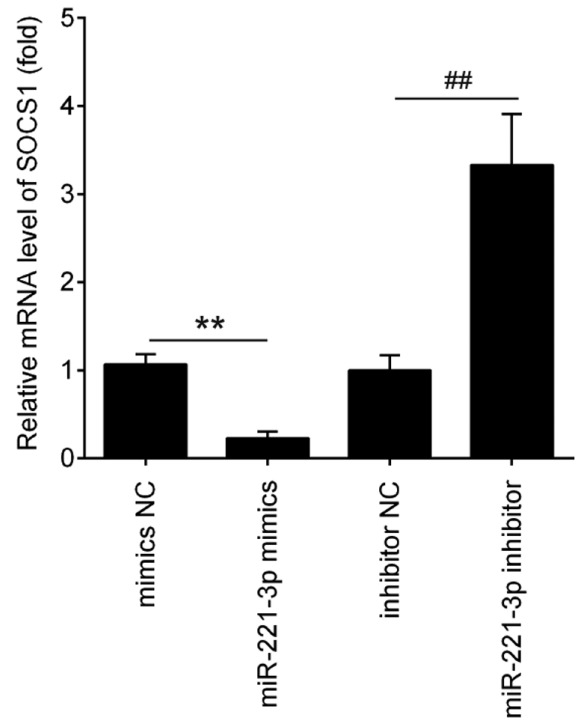

E

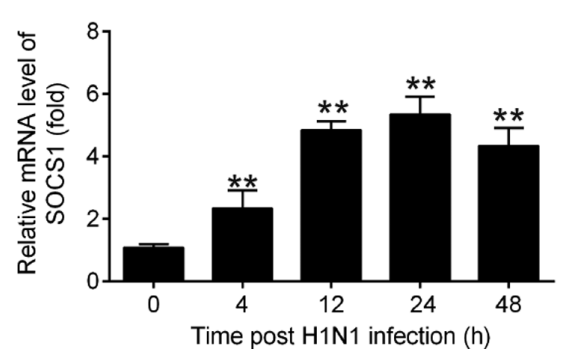

B

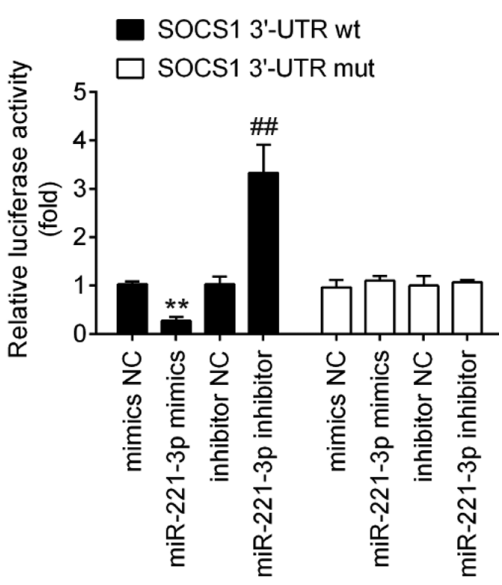

D

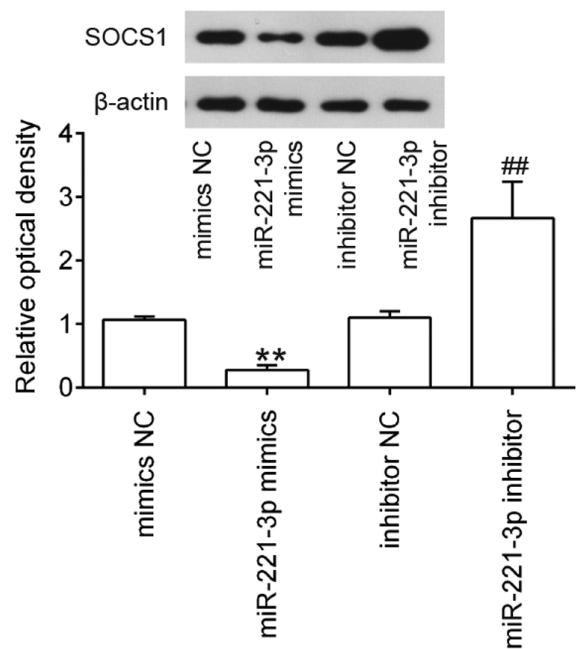

$\mathbf{F}$

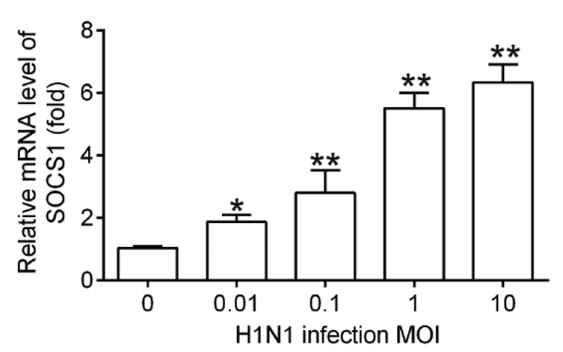

Figure 5. SOCS1 is a direct target of miR-221. (A) Putative binding site of miR-221 and SOCS1 with mut and wt 3' UTRs. (B) Luciferase assay of A549 cells co-transfected with firefly luciferase constructs containing the SOCS1 wt or mut 3' UTRs and miR-221 mimics, mimics NC, miR-221 inhibitor or inhibitor $\mathrm{NC}$, as indicated $(\mathrm{n}=3)$. (C and D) mRNA and protein expression levels of SOCS1 were measured using RT-qPCR and western blotting after miR-221 mimics/inhibitor transfection in A549 cells. A549 cells were infected with IAV either at indicated time at (E) a MOI of 1 or at (F) indicated MOIs for $24 \mathrm{~h}$, and then the cells were harvested for further RT-qPCR analysis of SOCS1 expression. Data are presented as the mean \pm SD of three individual experiments. ${ }^{*} \mathrm{P}<0.05$ and ${ }^{* *} \mathrm{P}<0.01$ vs. mock or mimics NC group; ${ }^{\# \#} \mathrm{P}<0.01$ vs. inhibitor NC group. SOCS1, suppressor of cytokine signaling 1; UTR, untranslated region; wt, wild-type; mut, mutant; MOI, multiplicity of infection; NC, negative control; RT-q, reverse transcription-quantitative; hsa, Homo sapiens.

immune responses by downregulating miR-221 expression. This may improve our understanding of IAV pathogenesis.

Innate immune responses to viral infection induce the production of type-I IFN through a cascade of complex signaling pathways that play critical roles in antiviral immunity (34). It has been demonstrated that the IAV possesses multiple strategies to attenuate the type-I IFN-mediated antiviral response for successful replication. Viral coding proteins, including NS1, polymerase basic protein 2 (PB2) and polymerase basic protein 1-frame 2 (PB1-F2), have been reported to block the signaling pathways involved in type-I IFN synthesis $(35,36)$. For example, the IAV NS1 protein, the major IFN antagonist of
IAVs, can inhibit JAK/STAT signaling activation by increasing SOCS1 and SOCS3 expression (37). The H protein of IAVs has been shown to induce degradation of the type-I IFN receptor 1, thus suppressing the expression of IFN-stimulated antiviral proteins (38). In addition, PB2, another non-structural protein of IAVs, interacts with the mitochondrial antiviral signaling protein, a key component of the IFN synthesis pathway, thus impairing IFN- $\beta$ production without affecting viral replication in vitro (39). Therefore, it is important to explore how IAV escapes IFN-I-mediated antiviral immune responses.

Increasing evidence has reported that IAV can change the expression profiles of host miRNA, and some host miRNA 
A

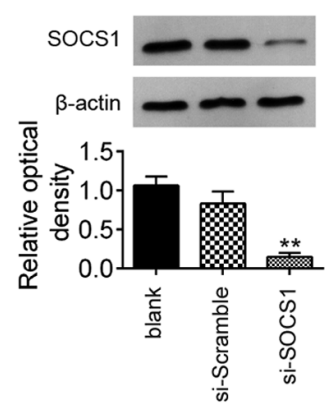

E

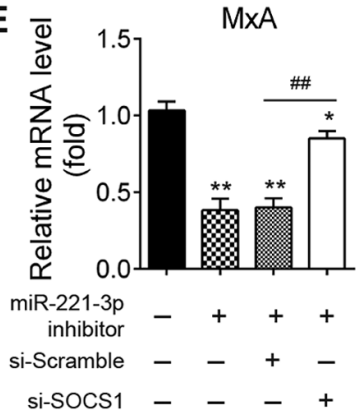

B

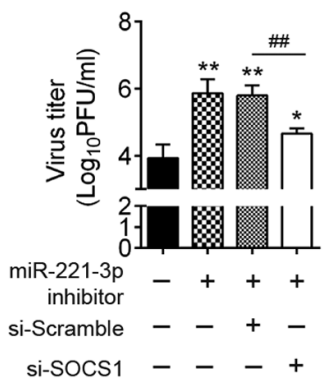

$\mathbf{F}$

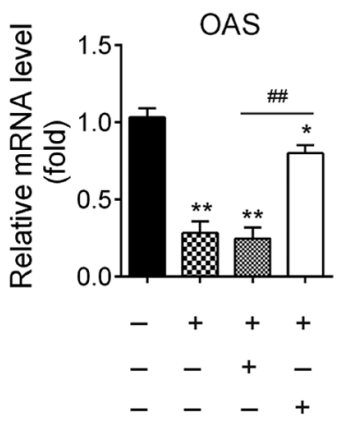

C

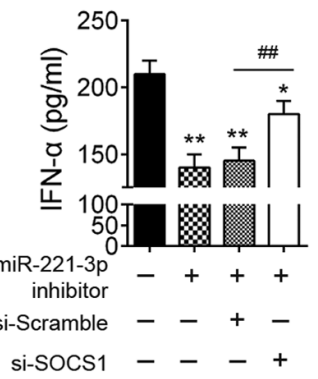

G

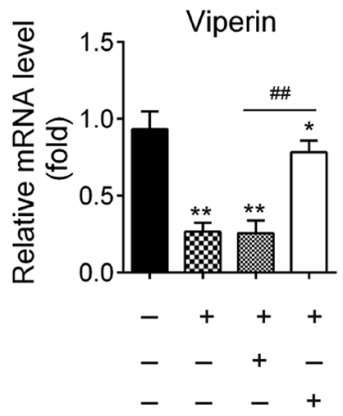

D

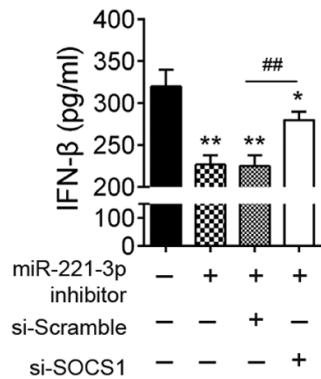

$\mathrm{H}$

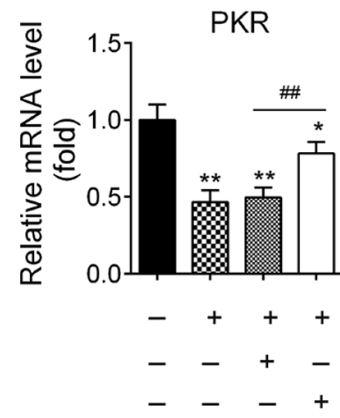

Figure 6. miR-221 promotes IAV replication by targeting SOCS1. A549 cells were transfected with miR-221 inhibitor, si-SOCS1, or both. (A) Expression levels of SOCS1 protein were measured using western blotting. (B) Viral titers in the cell cultures were determined by plaque assay using 12-well plates. (C and D) ELISA assay was performed to measure IFN- $\alpha$ and IFN $\beta$ expression. (E-H) Reverse transcription-quantitative PCR assay was performed to measure IFN-stimulated gene expression (MxA, OAS, viperin and PKR). Data are presented as the mean \pm SD of three individual experiments. ${ }^{*} \mathrm{P}<0.05$ and ${ }^{* *} \mathrm{P}<0.01$ vs. Blank group; ${ }^{\#} \mathrm{P}<0.01$ vs. miR-221 inhibitor + si-scramble group. NC, negative control; IAV, influenza A virus; miR, microRNA; OAS, 2'-5'-oligoadenylate synthase 2; SOCS1, suppressor of cytokine signaling 1; si, small interfering; MxA, myxovirus influenza resistance 1; PKR, interferon-inducible double-stranded RNA-dependent protein kinase activator A; PFU, plaque-forming unit.

molecules participate in various types of viral infection by modulating type-I IFNs. For example, Zhang et al (20) demonstrated that IAV infection could upregulate miR-132-3p and that the miR-132-3p/IRF1 axis impaired the type-I IFN-mediated antiviral defense, thus promoting IAV replication. Zhang et al (40) showed that miR-146a was significantly upregulated during IAV infection and miR-146a downregulation led to a significant reduction in IAV replication by enhancing the type-I IFN response. Shi et al (41) found that miR-21-3p downregulated fibroblast growth factor 2 expression to accelerate IAV replication by impairing the IFN response. The current study demonstrated that IAV infection modulated the expression profile of miRNA in host cells. In particular, miR-221 was one of the most notably downregulated miRNA molecules during IAV infection. Moreover, IAV infection regulated miR-221 expression in a timeand dose-dependent manner. These data suggested that miR-221 may play an important role in IAV infection. However, whether miR-221 participates in influenza virus-mediated inhibition of type-I IFN-mediated antiviral responses is not clear. Previous studies have shown that miR-221 can be induced by several viruses and influence virus replication through the regulation of the host antiviral innate immune response. Yan et al (22) found that miR-221 restricts HCMV replication by promoting type-I IFN production. Another study showed that miR-221 inhibits human papillomavirus 16E1-E2-mediated DNA replication by regulating the type-I IFN signaling pathway (23). In addition, Xu et al (42) reported that miR-221 could accentuate IFN anti-HCV effect by targeting SOCS1 and SOCS3. In the present study, loss- and gain-of-function experiments demonstrated that IAV replication was inhibited by overexpression of miR-221, while promoted by miR-221 inhibition, as determined by virus titers. Moreover, overexpression of miR-221 inhibited type-I IFN-mediated antiviral defense of host cells, whereas miR-221 inhibition had an opposite effect, indicating that miR-221 contributes to IAV infection through negative modulation of the type-I IFN response.

Following the identification of the roles of miR-221 in IAV infection, the underlying mechanism was further explored. SOCS1 was identified as a direct target of miR-221. SOCS1, a negative regulator of the IFN-I signaling pathway, has been implicated in regulating immune response and viral pathogenesis (43-45). For example, upregulation of SOCS1 precedes type-I IFN signaling activation and inhibits the IFN-inducible antiviral response as well as chemokine induction (46). Respiratory syncytial virus infection upregulates SOCS1 expression in HEp-2 cells, and suppression of SOCS1 inhibits viral replication through activating type-I IFN signaling (47). Thus, it was speculated that IAV escapes IFN-I antiviral activity via the miR-221/SOCS1 axis. The current study found that the expression of SOCS1 was increased during IAV infection in a dose- and time-dependent manner, confirming that IAV-induced miR-221 is responsible for the increased SOCS1. Moreover, the promoting effects of miR-221-knockdown on IAV replication were abrogated by SOCS1 inhibition.

It is well-known that $\mathrm{NF}-\kappa \mathrm{B}$ functions as an important coordinator of immune responses (48). Some viruses utilize $\mathrm{NF}-\kappa \mathrm{B}$ modulation to escape from host clearance, as well as to enhance viral replication $(49,50)$. Since the $N F-\kappa B$ signaling pathway acts downstream of SOCS1, the present study sought to determine whether miR-221 inhibition could influence the activation of the NF- $\mathrm{BB}$ signaling pathway. Thus, the key kinases in the $\mathrm{NF}-\kappa \mathrm{B}$ pathway were examined. miR-221 inhibition 
A

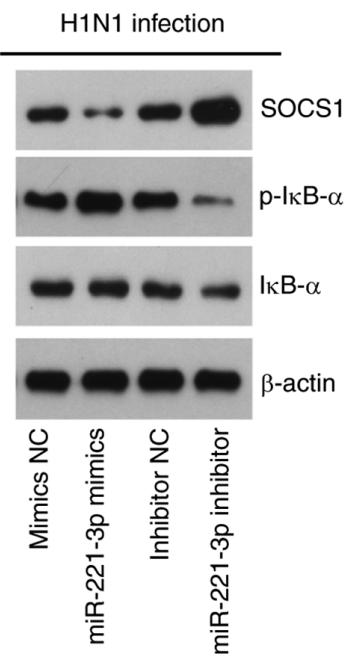

B

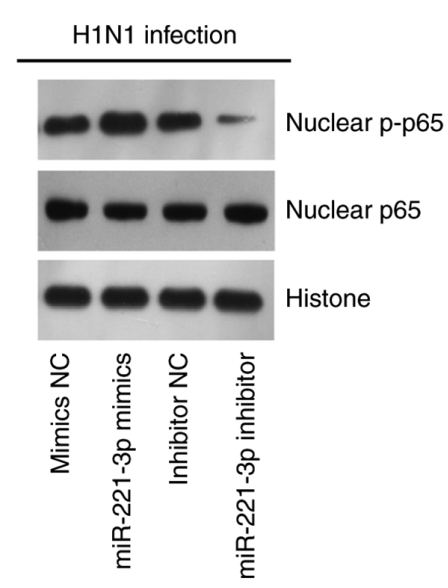

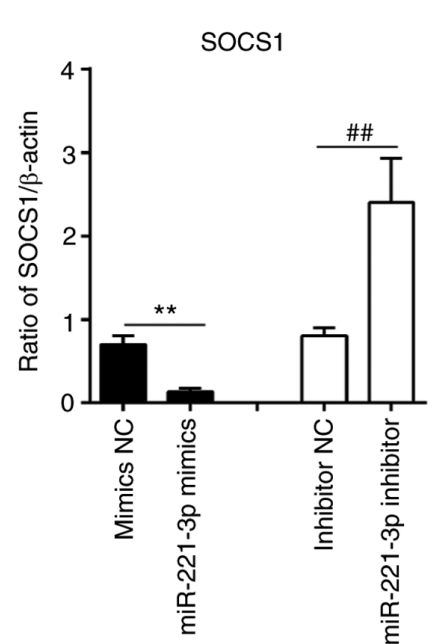
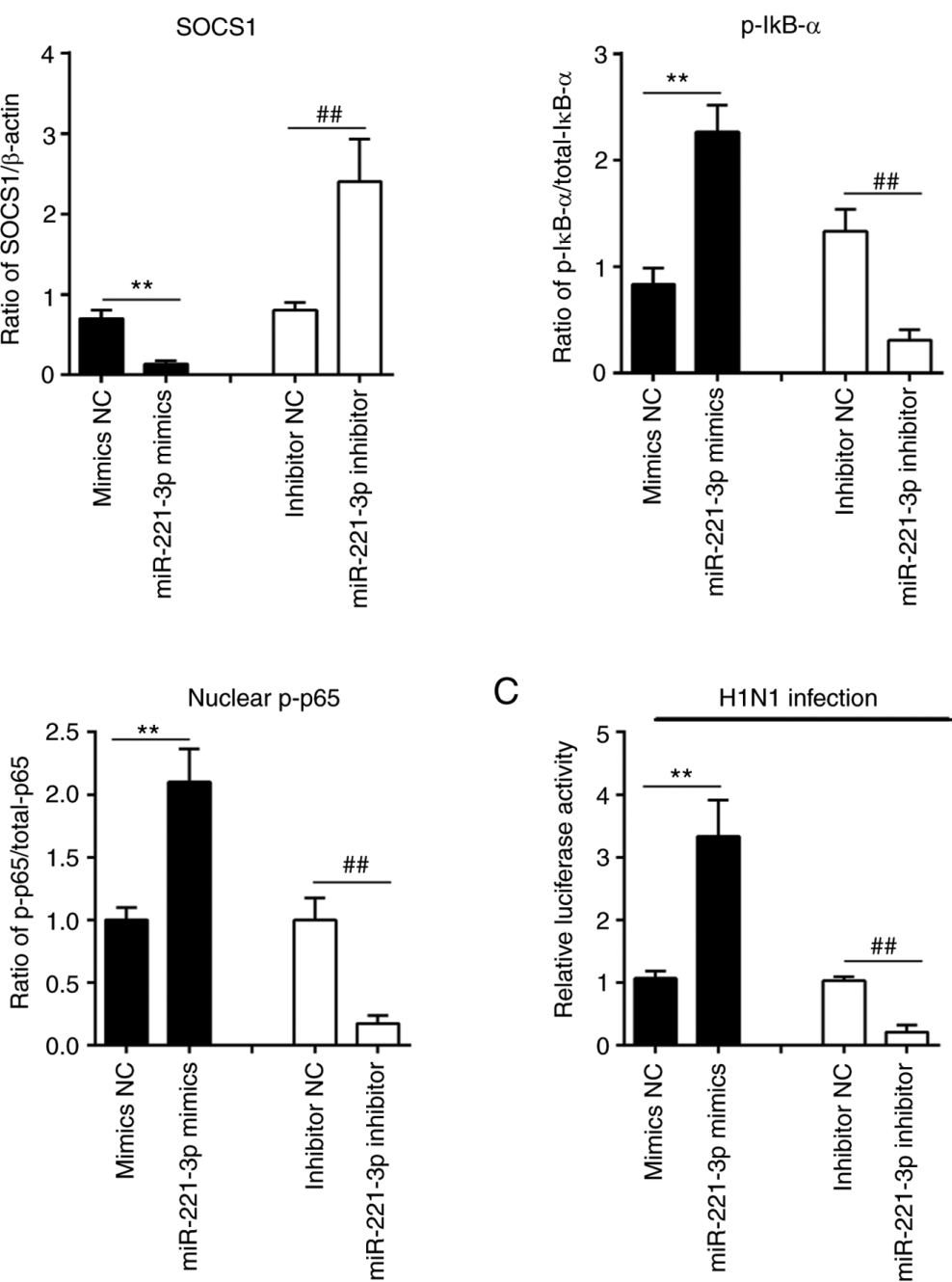

C

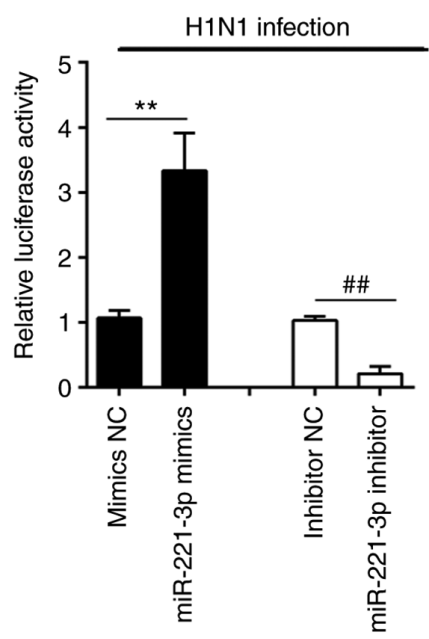

Figure 7. miR-221 positively regulates SOCS1-mediated activation of the NF-kB pathway. A549 cells were transfected with miR-221 mimics, mimics NC, miR-221 inhibitor and inhibitor NC. (A) Cell and supernatant were harvested, and then western blotting was performed to measure SOCS1 and p-IкB- $\alpha$ expression. (B) Expression levels of nuclear p-p65 and nuclear p65 were measured using western blotting. (C) NF-kB activity was quantified using a luciferase assay kit. Data are presented as the mean $\pm \mathrm{SD}$ of three individual experiments. ${ }^{* *} \mathrm{P}<0.01$ vs. mimics $N C$ group; ${ }^{\# \#} \mathrm{P}<0.01$ vs. inhibitor NC group. SOCS1, suppressor of cytokine signaling 1; NC, negative control; p-, phosphorylated; H1N1, hemagglutinin 1 neuraminidase 1; IкB- $\alpha$, NF- $\kappa \mathrm{B}$ inhibitor $\alpha$.

suppressed the activation of the NF- $\mathrm{KB}$ signaling pathway by increasing SOCS1 expression, whilst miR-221-overexpression had the opposite result in IAV-infected A549 cells. These findings suggested that IAV may escape innate immunity through the miR-221/SOCS1/NF-kB pathway.

There are several limitations of the present study. All these results were obtained from in vitro experiments; thus, influenza virus challenge experiments should be performed in vivo to test whether upregulation of miR-221 by agomir-221 injection has a protective role during IAV infection in mice. The role of miR-221 in the airway epithelial cells should also be investigated, such as mouse alveolar macrophages (RAW264.7) that serve as the primary target for virus infection and replication $(51,52)$. Thus, additional experiments should be carried out to test how IAV attenuates the type-I IFN-mediated antiviral response.

In conclusion, the current study demonstrated that downregulation of miR-221 inhibited the type-I IFN-mediated immune response by targeting the SOCS1/NF- $\mathrm{\kappa B}$ pathway, and thereby promoting IAV replication. These findings suggested that miR-221 may be an important therapy target for IAV control in future.

\section{Acknowledgements}

Not applicable.

\section{Funding}

No funding was received.

\section{Availability of data and materials}

The datasets used and/or analyzed during the current study are available from the corresponding author on reasonable request.

\section{Authors' contributions}

NZ, YM, YTi, YZ, YTa and SH performed all the experiments and collected the data. NZ conceived and designed the study. 
$\mathrm{NZ}$ wrote the main manuscript and analyzed the data. NZ, YM and YTi confirmed the authenticity of all raw data. All authors read and approved the final manuscript.

\section{Ethics approval and consent to participate}

Not applicable.

\section{Patient consent for publication}

Not applicable.

\section{Competing interests}

The authors declare that they have no competing interests.

\section{References}

1. Smith DJ, Lapedes AS, de Jong JC, Bestebroer TM, Rimmelzwaan GF, Osterhaus AD and Fouchier RA: Mapping the antigenic and genetic evolution of influenza virus. Science 305 371-376, 2004.

2. Cheung CY, Poon LL, Lau AS, Luk W, Lau YL, Shortridge KF, Gordon S, Guan Y and Peiris JS: Induction of proinflammatory cytokines in human macrophages by influenza A (H5N1) viruses: A mechanism for the unusual severity of human disease? Lancet 360: 1831-1837, 2002.

3. Kim H, Webster RG and Webby RJ: Influenza virus: Dealing with a drifting and shifting pathogen. Viral Immunol 31: 174-183, 2018.

4. Medina RA and Garcia-Sastre A: Influenza A viruses: New research developments. Nat Rev Microbiol 9: 590-603, 2011.

5. Hiscott J: Convergence of the NF-kappaB and IRF pathways in the regulation of the innate antiviral response. Cytokine Growth Factor Rev 18: 483-490, 2007.

6. Julkunen I, Sareneva T, Pirhonen J, Ronni T, Melén K and Matikainen S: Molecular pathogenesis of influenza A virus infection and virus-induced regulation of cytokine gene expression. Cytokine Growth Factor Rev 12: 171-180, 2001.

7. Veckman V, Osterlund P, Fagerlund R, Melén K, Matikainen S and Julkunen I: TNF-alpha and IFN-alpha enhance influenza-A-virus-induced chemokine gene expression in human A549 lung epithelial cells. Virology 345: 96-104, 2006.

8. Li R and Wang L: Baicalin inhibits influenza virus A replication via activation of type I IFN signaling by reducing miR-146a. Mol Med Rep 20: 5041-5049, 2019.

9. Downey J, Pernet E, Coulombe F, Allard B, Meunier I, Jaworska J, Qureshi S, Vinh DC, Martin JG, Joubert P and Divangahi M RIPK3 interacts with MAVS to regulate type I IFN-mediated immunity to influenza A virus infection. PLoS Pathog 13: e1006326, 2017.

10. Munir M, Zohari S and Berg M: Non-structural protein 1 of avian influenza $A$ viruses differentially inhibit NF- $\mathrm{kB}$ promoter activation. Virol J 8: 383, 2011

11. Ruckle A, Haasbach E, Julkunen I, Planz O, Ehrhardt C and Ludwig S: The NS1 protein of influenza A virus blocks RIG-I-mediated activation of the noncanonical NF- $\kappa \mathrm{B}$ pathway and p52/RelB-dependent gene expression in lung epithelial cells. J Virol 86: 10211-10217, 2012.

12. Gao S, Song L, Li J, Zhang Z, Peng H, Jiang W, Wang Q, Kang T, Chen $S$ and Huang W: Influenza A virus-encoded NS1 virulence factor protein inhibits innate immune response by targeting IKK. Cell Microbiol 14: 1849-1866, 2012.

13. Hayashi T, MacDonald LA and Takimoto T: Influenza A virus protein PA-X contributes to viral growth and suppression of the host antiviral and immune responses. J Virol 89: 6442-6452, 2015 .

14. Ambros V: The functions of animal microRNAs. Nature 431: 350-355, 2004

15. Kincaid RP and Sullivan CS: Virus-encoded microRNAs: An overview and a look to the future. PLoS Pathog 8: e1003018, 2012.

16. Cullen BR: Viruses and microRNAs. Nat Genet 38 (Suppl 1): S25-S30, 2006.
17. Sullivan CS, Grundhoff A, Tevethia S, Treisman R, Pipas JM and Ganem D: Expression and function of microRNAs in viruses great and small. Cold Spring Harb Symp Quant Biol 71: 351-356, 2006.

18. Ho BC, Yu IS, Lu LF, Rudensky A, Chen HY, Tsai CW, Chang YL, Wu CT, Chang LY, Shih SR, et al: Inhibition of miR-146a prevents enterovirus-induced death by restoring the production of type I interferon. Nat Commun 5: 3344, 2014.

19. Chen Y, Chen J, Wang H, Shi J, Wu K, Liu S, Liu Y and Wu J: HCV-induced miR-21 contributes to evasion of host immune system by targeting MyD88 and IRAK1. PLoS Pathog 9: e1003248, 2013

20. Zhang F, Lin X, Yang X, Lu G, Zhang Q and Zhang C: MicroRNA-132-3p suppresses type I IFN response through targeting IRF1 to facilitate H1N1 influenza A virus infection. Biosci Rep 39: BSR20192769, 2019.

21. Zhu X, He Z, Hu Y, Wen W, Lin C, Yu J, Pan J, Li R, Deng H, Liao S, et al: MicroRNA-30 $\mathrm{e}^{*}$ suppresses dengue virus replication by promoting NF- $\mathrm{KB}$-dependent IFN production. PLoS Negl Trop Dis 8: e3088, 2014

22. Yan B, Ma H, Jiang S, Shi J, Yang Z, Zhu W, Kong C, Chen L, Yan $\mathrm{H}$ and Ma C: microRNA-221 restricts human cytomegalovirus replication via promoting type I IFN production by targeting SOCS1/NF-кB pathway. Cell Cycle 18: 3072-3084, 2019.

23. Lu H and Gu X: MicroRNA-221 inhibits human papillomavirus 16 E1-E2 mediated DNA replication through activating SOCS1/Type I IFN signaling pathway. Int J Clin Exp Pathol 12: 1518-1528, 2019.

24. Du H, Cui S, Li Y, Yang G, Wang P, Fikrig E and You F: MiR-22 negatively regulates innate anti-viral response. PLoS One 13: $\mathrm{e} 0200385,2018$.

25. Livak KJ and Schmittgen TD: Analysis of relative gene expression data using real-time quantitative PCR and the 2(-Delta Delta C(T)) method. Methods 25: 402-408, 2001

26. Ding Y, Wang L, Zhao Q, Wu Z and Kong L: MicroRNA-93 inhibits chondrocyte apoptosis and inflammation in osteoarthritis by targeting the TLR4/NF- $\mathrm{BB}$ signaling pathway. Int J Mol Med 43: 779-790, 2019.

27. Nakamura S, Horie M, Daidoji T, Honda T, Yasugi M, Kuno A, Komori T, Okuzaki D, Narimatsu H, Nakaya T and Tomonaga K: Influenza A virus-induced expression of a GalNAc transferase, GALNT3, via MicroRNAs is required for enhanced viral replication. J Virol 90: 1788-1801, 2015.

28. Terán-Cabanillas E, Montalvo-Corral M, Silva-Campa E, Caire-Juvera G, Moya-Camarena SY and Hernández J: Production of interferon $\alpha$ and $\beta$, pro-inflammatory cytokines and the expression of suppressor of cytokine signaling (SOCS) in obese subjects infected with influenza A/H1N1. Clin Nutr 33: 922-926, 2014

29. Subbarao K and Joseph T: Scientific barriers to developing vaccines against avian influenza viruses. Nat Rev Immunol 7 : 267-278, 2007.

30. Chiang C, Chen GW and Shih SR: Mutations at alternative 5 splice sites of M1 mRNA negatively affect influenza A virus viability and growth rate. J Virol 82: 10873-10886, 2008.

31. Pichlmair A, Schulz O, Tan CP, Näslund TI, Liljeström P, Weber F and Reis e Sousa C: RIG-I-mediated antiviral responses to single-stranded RNA bearing 5'-phosphates. Science 314: 997-1001, 2006.

32. Prêle CM, Woodward EA, Bisley J, Keith-Magee A, Nicholson SE and Hart PH: SOCS1 regulates the IFN but not NFkappaB pathway in TLR-stimulated human monocytes and macrophages. J Immunol 181: 8018-8026, 2008.

33. Nakahara T, Tanaka K, Ohno S, Egawa N, Yugawa T and Kiyono T: Activation of NF- $\kappa$ B by human papillomavirus $16 \mathrm{E} 1$ limits E1-dependent viral replication through degradation of E1. J Virol 89: 5040-5059, 2015.

34. Akira S, Uematsu S and Takeuchi O: Pathogen recognition and innate immunity. Cell 124: 783-801, 2006.

35. Gack MU, Albrecht RA, Urano T, Inn KS, Huang IC, Carnero E, Farzan M, Inoue S, Jung JU and García-Sastre A: Influenza A virus NS1 targets the ubiquitin ligase TRIM25 to evade recognition by the host viral RNA sensor RIG-I. Cell Host Microbe 5: 439-449, 2009.

36. Varga ZT, Ramos I, Hai R, Schmolke M, García-Sastre A, Fernandez-Sesma A and Palese P: The influenza virus protein PB1-F2 inhibits the induction of type I interferon at the level of the MAVS adaptor protein. PLoS Pathog 7: e1002067, 2011.

37. Stranden AM, Staeheli P and Pavlovic J: Function of the mouse $\mathrm{Mx} 1$ protein is inhibited by overexpression of the $\mathrm{PB} 2$ protein of influenza virus. Virology 197: 642-651, 1993. 
38. Xia C, Vijayan M, Pritzl CJ, Fuchs SY, McDermott AB and Hahm B: Hemagglutinin of influenza A virus antagonizes type I interferon (IFN) responses by inducing degradation of type I IFN receptor 1. J Virol 90: 2403-2417, 2015.

39. Graef KM, Vreede FT, Lau YF, McCall AW, Carr SM, Subbarao K and Fodor E: The PB2 subunit of the influenza virus RNA polymerase affects virulence by interacting with the mitochondrial antiviral signaling protein and inhibiting expression of beta interferon. J Virol 84: 8433-8445, 2010.

40. Zhang F, Sun X, Zhu Y and Qin W: Downregulation of miR-146a inhibits influenza A virus replication by enhancing the type I interferon response in vitro and in vivo. Biomed Pharmacother 111: 740-750, 2019.

41. Shi J, Feng P and Gu T: MicroRNA-21-3p modulates FGF2 to facilitate influenza A virus $\mathrm{H} 5 \mathrm{~N} 1$ replication by refraining type I interferon response. Biosci Rep: May 19, 2020. doi: 10.1042/BSR20200158.

42. Xu G, Yang F, Ding CL, Wang J, Zhao P, Wang W and Ren H: MiR-221 accentuates IFN's anti-HCV effect by downregulating SOCS1 and SOCS3. Virology 462-463: 343-350, 2014.

43. Kawai T and Akira S: Toll-like receptor and RIG-I-like receptor signaling. Ann N Y Acad Sci 1143: 1-20, 2008.

44. Alexander WS and Hilton DJ: The role of suppressors of cytokine signaling (SOCS) proteins in regulation of the immune response. Annu Rev Immunol 22: 503-529, 2004.

45. Akhtar LN and Benveniste EN: Viral exploitation of host SOCS protein functions. J Virol 85: 1912-1921, 2011.

46. Zheng J, Yang P, Tang Y, Pan Z and Zhao D: Respiratory syncytial virus nonstructural proteins upregulate SOCS1 and SOCS3 in the different manner from endogenous IFN signaling. J Immunol Res 2015: 738547, 2015.
47. Hashimoto K, Ishibashi K, Ishioka K, Zhao D, Sato M, Ohara S, Abe Y, Kawasaki Y, Sato Y, Yokota S, et al: RSV replication is attenuated by counteracting expression of the suppressor of cytokine signaling (SOCS) molecules. Virology 391: 162-170, 2009.

48. Deng L, Zeng Q, Wang M, Cheng A, Jia R, Chen S, Zhu D, Liu M, Yang Q, Wu Y, et al: Suppression of NF- $\kappa$ B activity: A viral immune evasion mechanism. Viruses 10: 409, 2018.

49. Yeh JX, Park E, Schultz KLW and Griffin DE: NF- $\kappa$ B Activation promotes alphavirus replication in mature neurons. J Virol 93: e01071-19, 2019.

50. Wei F, Jiang Z, Sun H, Pu J, Sun Y, Wang M, Tong Q, Bi Y, Ma X, Gao GF and Liu J: Induction of PGRN by influenza virus inhibits the antiviral immune responses through downregulation of type I interferons signaling. PLoS Pathog 15: e1008062, 2019.

51. Kumagai Y, Takeuchi O, Kato H, Kumar H, Matsui K, Morii E, Aozasa K, Kawai T and Akira S: Alveolar macrophages are the primary interferon-alpha producer in pulmonary infection with RNA viruses. Immunity 27: 240-252, 2007.

52. Newby CM, Sabin L and Pekosz A: The RNA binding domain of influenza A virus NS1 protein affects secretion of tumor necrosis factor alpha, interleukin-6, and interferon in primary murine tracheal epithelial cells. J Virol 81: 9469-9480, 2007. 